\title{
Disorders of cerebrovascular angioarchitectonics and microcirculation in the etiology and pathogenesis of Alzheimer's disease
}

\author{
Ivan V. Maksimovich \\ Clinic of Cardiovascular Diseases Named after Most Holy John Tobolsky, Moscow, Russia; carvasc@yandex.ru
}

Received 3 August 2013; revised 16 September 2013; accepted 25 September 2013

Copyright (C) 2013 Ivan V. Maksimovich. This is an open access article distributed under the Creative Commons Attribution License, which permits unrestricted use, distribution, and reproduction in any medium, provided the original work is properly cited.

\section{ABSTRACT}

There have recently appeared many reports dedicated to cerebral hemodynamics disorders in AD. However, certain specific aspects of cerebral blood flow and microcirculation during this disease are not fully understood. This research focuses on the identification of particular features of cerebral angioarchitectonics and microcirculation at preclinical and clinical $A D$ stages and on the determination of their importance in $A D$ etiology and pathogenesis. 164 patients participated in the research: Test Group-81 patients with different AD stages; Control Group83 patients with etiologically different neurodegenerative brain lesions with manifestations of dementia and cognitive impairment but without AD. All patients underwent: assessment of cognitive function (MMSE), severity of dementia (CDR) and $A D$ stages (TDR), laboratory examination, computed tomography (CT), magnetic resonance imaging (MRI), brain scintigraphy (SG), rheoencephalography (REG) and cerebral multi-gated angiography (MUGA). All Test Group patients, irrespective of their AD stage, had abnormalities of the cerebral microcirculation manifested in dyscirculatory angiopathy of Alzheimer's type (DAAT), namely: reduction of the capillary bed in the hippocampus and frontal-parietal regions; development of multiple arterio-venous shunts in the same regions; early venous dumping of arterial blood through these shunts with simultaneous filling of arteries and veins; development of abnormally enlarged lateral venous trunks that receive blood from the arterio-venous shunts; anomalous venous congestion at the border of frontal and parietal region; increased loop formation of distal intracranial ar- terial branches. Control group patients did not have combinations of such changes. These abnormalities are specific for $A D$ and can affect amyloid beta metabolism contributing to its accumulation in the brain tissue and thereby stimulating $A D$ progression.

Keywords: Alzheimer's Disease; Dementia, TDR; Microcirculation; Microcirculatory Disorders; Dyscirculatory Angiopathy of Alzheimer's Type; DAAT

\section{INTRODUCTION}

According to the Alzheimer's Association in 2013, one of eight Americans older than 60 has memory impairments [1]. The number of patients suffering from Alzheimer's disease (AD) has been constantly growing in different parts of the world. In the US alone, the number of patients with $\mathrm{AD}$ aged 65 and older is expected to increase from 5.4 million to 13.8 - 16 million by 2050 [2].

$\mathrm{AD}$ has for long been considered a purely neurodegenerative disease, so the research has mainly focused on structural changes in the brain tissue during this disease [3-5]. The introduction of such radiological methods as CT, MRI and PET has made great progress in neuroimaging allowing to study in vivo the changes that occur in the brain tissue during various neurodegenerative processes as well as to differentiate various structural lesions [6-9]. The use of biomarkers in the diagnosis of $\mathrm{AD}$ has recently allowed visualizing the accumulation of amyloid-beta and tau [10-13].

Compared to research aimed at understanding morphological lesions, the study of the brain vascular system in AD is much less developed. Back in the 1930s, F. Morel, using the material of postmortem autopsy, revealed the presence of cerebral vascular changes in $\mathrm{AD}$ 
and described dysoric or drusoidal angiopathy [14]. His extremely important study went unnoticed, and there has been practically no research in this area [15]. Only recently there have appeared significant studies aimed at investigating cerebral blood flow abnormalities in $\mathrm{AD}$ [16-21] which has resulted in the overall recognition of the fact that hypoperfusion and changes in the morphology of capillaries are involved in the etiology and pathogenesis of AD [22-28].

As a result, there have appeared several hypotheses concerning the role of microvascular changes in the etiopathogenesis of the disease [28-36] which points to the need for further research in this area. It has recently been repeatedly stated in the guidelines of the National Institute on Aging/Alzheimer's Association [37,38].

The ongoing studies are mainly based on post-mortem autopsy material $[39,40]$, research on genetically modified animals $[26,28,41]$, identification of cerebral perfusion by means of scintigraphy (SG) [42], single-photon emission computed tomography (SPECT), positron emission tomography (PET) [27,43], perfusion weighted magnetic resonance imaging (Perfusion MRI or PWI) [27].

All these methods have their pros and cons, but they do not reflect the true antemortem state of arterial, venous and microvascular system of the brain in AD.

Pathomorphological research allows of histological, cytological and cytochemical analysis of the brain. Research conducted on transgenic animals allows to explore models of the disease. Antemortem study of cerebral blood flow abnormalities is difficult enough. SPECT, PET and Perfusion MRI demonstrate average results and show the perfusion of the whole brain being unable to visualize the cerebral vascular system.

The present research focuses on visualizing by means of MUGA the features of cerebral angioarchitectonics and on microcirculatory disorders occurring at both preclinical AD stage and during its progress, as well as on comparison of these disorders with the changes in the vascular system of the brain in patients suffering from other common neurodegenerative diseases. The objective of this research is to systematize cerebrovascular disorders in $\mathrm{AD}$.

\section{METHODS}

\subsection{Patient Selection}

The whole research has been carried out with the approval of the Ethics Committee and with the consent of the examined patients and their relatives.

The research involved 164 patients from 28 to 79 years old (average age 67.5), 76 (46.34\%) male and 88 $(53.66 \%)$ female patients, suffering from various neurodegenerative brain lesions accompanied by the development of dementia and cognitive impairment of varying severity,

\subsection{Patient Examination}

The examination plan included the following methods:

- Assessment of cognitive functions was conducted by means of Mini-Mental State Examination (MMSE) [44].

- Clinical determination of the severity of dementia was made according to the Clinical Dementia Rating scale (CDR) [45].

- Tomographic identification of AD stages was performed among Test Group patients using the Tomography Dementia Rating scale (TDR) during CT and MRI examination [46-49]. This method allows to determine not only clinical but also pre-clinical AD stages by the determination of the severity of atrophic changes in the temporal lobes of the brain.

- Laboratory examination was performed according to the schemes generally accepted in iterventional neuroangiology including coagulologic, biochemical and clinical tests.

- Scintigraphy (SG) of the brain was carried out on a gamma camera (Ohio Nuclear, US) following the classical method in dynamic and static mode with TC $99 \mathrm{M}$ pertechnetat $555[20,21,30,32]$.

- Rheoencephalography (REG) was conducted by means of "Reospektr-8" (Neurosoft, Russia) in accordance with the standard automated method with the identification of abnormalities of pulse blood flow in the cerebral hemispheres $[22,32]$.

- CT and MRI of the brain were performed on "Somatom" (Siemens), "Hi Speed" (GE), "Tomoscan" (Philips), "Apetro Eterna" (Hitachi) following the ATAA (Advance Tomo Area Analysis) procedure allowing to determine the volume of the temporal lobes of the brain with subsequent determination of the severity of the degree of atrophy as a percentage from the total natural weight of the unaffected lobe tissue [21, 46-48].

- Cerebral multi-gated angiography (MUGA) of the brain was performed on apparatus "Advantx" (GE) following the classical method of transfemoral access. Synchronously, taking into account the start and rate of administration, $10-12 \mathrm{ml}$ of Omnipack 350 was introduced intra-carotidally and $7-8 \mathrm{ml}$ intra-vertebrally. The registration was carried out in direct and side projections in constant subtraction mode at a speed of 25 frames per second. Further on, frame by frame analysis of the angiograms received in each phase contrast was conducted $[20,21,32,42]$. Capillary density contrast analysis was performed at the corresponding phase by means of an automatic method using computer program "Angio vision" based on the determination of the degree of 
blackening of the corresponding part of the image $[20,21,42]$.

\subsection{Test Group}

$81(49.39 \%)$ patients from 34 to 79 years of age (average age 67), 28 (34.57\%) male and $53(65.43 \%)$ female, suffering from various AD stages who, according to The Clinical Dementia Rating scale (CDR) [45] and the Tomography Dementia Rating scale (TDR) [46-49] classifications, were divided into:

- Pre-clinical AD stage-TDR-0: a group of patients with a high risk of developing the disease who had initial involutive changes in the brain accompanied by growing memory disorders and each of whom had direct relatives suffering from AD. These patients did not have pronounced manifestations of dementia or serious cognitive impairment; however, the atrophy of the temporal lobes in the group amounted to 4.8\% (26 - 28 MMSE points)—9 (11.11\%) patients [46-49];

- Early AD stage - TDR-1: a group with mild dementia, mild cognitive impairment, had previously been diagnosed with $\mathrm{AD}$, history of the disease did not to exceed 2 years, the atrophy of the temporal lobes was $9 \%$ - 18\% which corresponds to CDR-1 (20 - 25 MMSE points) - 24 (29.63\%) patients;

- Middle AD stage-TDR-2: a group with mild dementia, sufficiently persistent cognitive impairment, had previously been diagnosed with $\mathrm{AD}$, medical history of 2 to 6 years, the atrophy of the temporal lobes was $19 \%$ - 32\% which corresponds to CDR-2 (12 - 19 MMSE points)-31 (38.27\%) patients;

- Late AD stage-TDR-3: a group with fairly severe dementia, gross cognitive impairment, had previously been diagnosed with AD, medical history of 7 to 12 years, the atrophy of the temporal lobes was 33\% $62 \%$ which corresponds to CDR-3 (7-11 MMSE points $)-17(20.99 \%)$ patients.

\subsection{Control Group}

$83(50.61 \%)$ patients from 28 to 78 years of age (av- erage age 68), 48 (57.83\%) male and 35 (42.17\%) female patients, with etiologically different neurodegenerative brain lesions accompanied by manifestations of dementia and cognitive impairment of varying severity but without AD.

These patients were divided into the following groups:

- A group with the initial stage of chronic cerebrovascular insufficiency of atherosclerotic genesis without any signs of persistent dementia or cognitive impairment. Those patients had individual complaints revealing abnormalities of cerebral hemodynamics$19(22.89 \%)$ patients of whom 7 patients had CDR-1;

- A group with sufficiently severe chronic cerebrovascular insufficiency of atherosclerotic genesis without gross occlusive vascular lesions of the brain. Those patients had MCI and the symptoms of mild beginning dementia-18 (21.69\%) patients of whom 13 had CDR-1 and 5 had CDR-2;

- A group with multiple atherosclerotic lesions of the brain, severe vascular dementia and cognitive impairment. Those patients' medical history showed recurrent transient abnormalities of cerebral blood flow and minor strokes-17 (20.48\%) patients of whom 11 had CDR-2 and 6 had CDR-3;

- A group with atherosclerotic (vascular) Parkinson's disease and manifestations of dementia-19 (22.89\%) patients of whom 10 had CDR-1 and 9 had CDR-2;

- A group with Binswanger's disease and manifestations of dementia-6 (7.23\%) patients of whom 1 had CDR-1, 2 had CDR-2 and 3 had CDR-3;

- A group with Parkinson's disease and manifestations of dementia-4 (4.82\%) patients of whom 1 had CDR-1 and 3 had CDR-2.

\section{RESULTS}

\subsection{Test Group}

According to $\mathrm{CT}$ and MRI:

- AD-specific neurodegenerative changes in the brain manifested in temporal lobes atrophy which at different stages of the disease lead to $4 \%-62 \%$ reduction in tissue mass were detected in $81(100 \%)$ cases (Table 1);

- individual cerebral neurodegenerative changes were observed in a limited number of cases (Table 1).

According to SG, the slowing of blood flow in the cerebral hemispheres was detected in $81(100 \%)$ cases.

According to REG, pulse blood volume reduction in the carotid system was detected in $81(100 \%)$ cases.

Elevated level of lipids in the blood was detected in 34 $(41.98 \%)$ cases.

Hypercoagulation was observed in 37 (45.68\%) cases.

- Absence (or they were poorly expressed) of atherosclerotic changes of extra and intracranial arteries$81(100 \%)$ patients (Figures 1, 2 and 6);

- Reduction of capillary contrast phase in the form of microvascular cone-shaped spots in the projection of the hippocampus and the fronto-parietal regions -81 (100\%) patients (Figures 1-3);

- Multiple arterio-venous shunts in the region of the anterior villous artery supplying the hippocampus and in the region of the arterial branches supplying the frontoparietal cortex - $81(100 \%)$ patients (Figures 1, 2 and 4);

- Early venous dumping of arterial blood with simultaneous filling of the arteries and veins in the temporal and fronto-parietal brain regions-81 (100\%) patients (Figure 2);

- The development of abnormally enhanced lateral venous trunks that receive blood from the arterio- 
Table 1. CT and MRI data in test and control group patients.

\begin{tabular}{|c|c|c|c|}
\hline Number of Patients: N-164 & $\begin{array}{c}\text { Test Group } \\
\text { (Alzheimer's Disease): N-81 }\end{array}$ & $\begin{array}{c}\text { Control Group } \\
\text { (Other Brain Lesions): N-83 }\end{array}$ & p (Chi-Square) \\
\hline \multicolumn{4}{|c|}{ Atrophic Changes in the Temporal Lobes of the Brain } \\
\hline $\begin{array}{l}4 \%-8 \% \text { Reduction of the temporal } \\
\text { lobes of the brain-TDR- } 0\end{array}$ & 9 & 0 & 0.0054 \\
\hline $\begin{array}{l}9 \%-18 \% \text { Reduction of the temporal } \\
\text { lobes of the brain-TDR-1 }\end{array}$ & 24 & 0 & $<0.005$ \\
\hline $\begin{array}{l}19 \%-32 \% \text { Reduction of the temporal } \\
\text { lobes of the brain - TDR- } 2\end{array}$ & 31 & 0 & $<0.005$ \\
\hline $\begin{array}{l}33 \%-62 \% \text { Reduction of the temporal } \\
\text { lobes of the brain -TDR- } 3\end{array}$ & 17 & 0 & $<0.005$ \\
\hline \multicolumn{4}{|c|}{ General Cerebral Changes } \\
\hline $\begin{array}{l}\text { Multiple deposits of calcium salts } \\
\text { in intracranial vessels }\end{array}$ & 0 & 79 & $<0.005$ \\
\hline Multiple postischemic macrocysts (over $5 \mathrm{~mm}$ ) & 0 & 17 & $<0.005$ \\
\hline Postischemic macrocysts ( $3-5 \mathrm{~mm})$ & 0 & 48 & $<0.005$ \\
\hline Leucoaraiosis & 0 & 25 & $<0.005$ \\
\hline Expansion of Sylvian fissures & 81 & 57 & $<0.005$ \\
\hline $\begin{array}{l}\text { Reduction of the temporal lobes of the } \\
\text { brain by } 0 \%-5 \% \text { in patients older than } 60\end{array}$ & 0 & 36 & $<0.005$ \\
\hline General neurodegenerative cortex changes & 31 & 49 & 0.012 \\
\hline Unocclusive hydrocephalus & 50 & 48 & 0.727 (none) \\
\hline
\end{tabular}

An analysis of $2 \times 2$ contingency tables for each of the parameters under study was made using the chi-square test which showed statistically significant differences for each of the parameters under study except for unocclusive hydrocephalus.

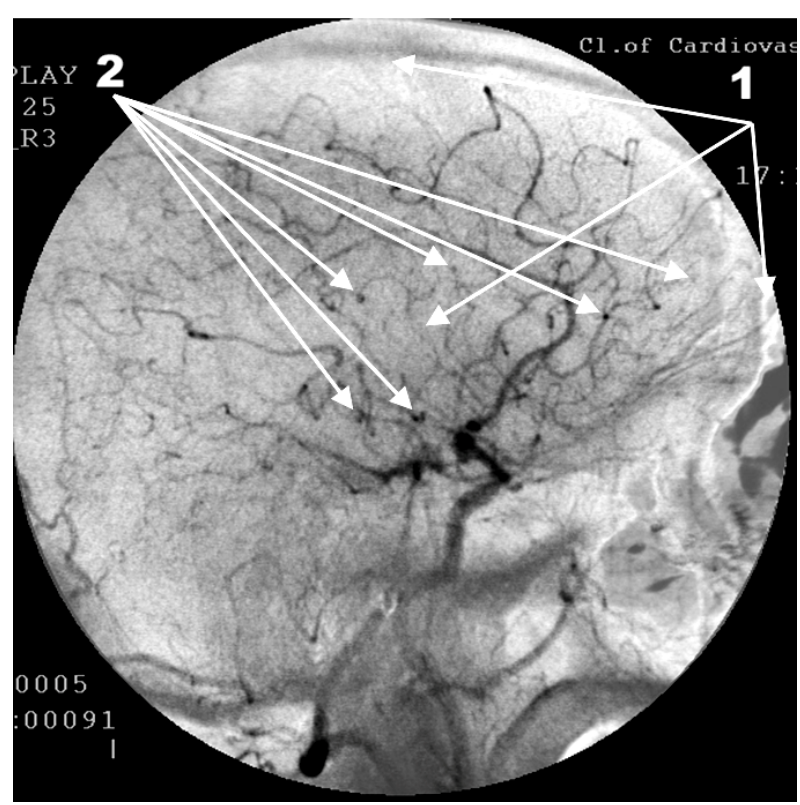

Figure 1. Patient Sh., 68 years old. Angiogram of the right internal carotid artery; TDR-3; lateral projection, arterial phase; Absence of atherosclerotic changes of intracranial vessels. 1: Development of hypovascular region; 2: Multiple arteriovenous shunts in fronto-parietal and temporal regions.

venous shunts in the temporal and fronto-parietal region-73 (90.12\%) patients (Figure 5);

- Anomalous venous congestion at the border of frontal and parietal lobe caused by the increased blood flow from the arterio-venous shunts-74 (91.36\%) patients
(Figures 5 and 6);

- Increased looping of distal intracranial arterial branches$64(79.02 \%)$ patients (Figure 3).

\subsection{Control Group}

According to CT and MRI:

- changes in the brain manifested in the local atrophy of the temporal lobes (specific to AD) were not identified in any case (Table 1);

- cerebral neurodegenerative changes were found in almost all cases (Table 1).

According to SG, the slowing of blood flow in the cerebral hemispheres was detected in all $83(100 \%)$ cases.

According to REG, pulse blood volume reduction in the carotid system was detected in all $83(100 \%)$ cases.

Elevated level of lipids in the blood was detected in 71 $(85.54 \%)$ cases.

Hypercoagulation was observed in $65(78.31 \%)$ cases.

Cerebral MUGA revealed the following disorders (Table 2):

- atherosclerotic changes of intracranial arteries-80 (96.39\%) cases;

- stenotic lesions of intracranial branches-63 (75.90\%) patients;

- occlusive lesions of intracranial branches-22 (26.51\%) patients;

- reduction of capillary phase contrast with typical boundaries in the projection of the hippocampus and 


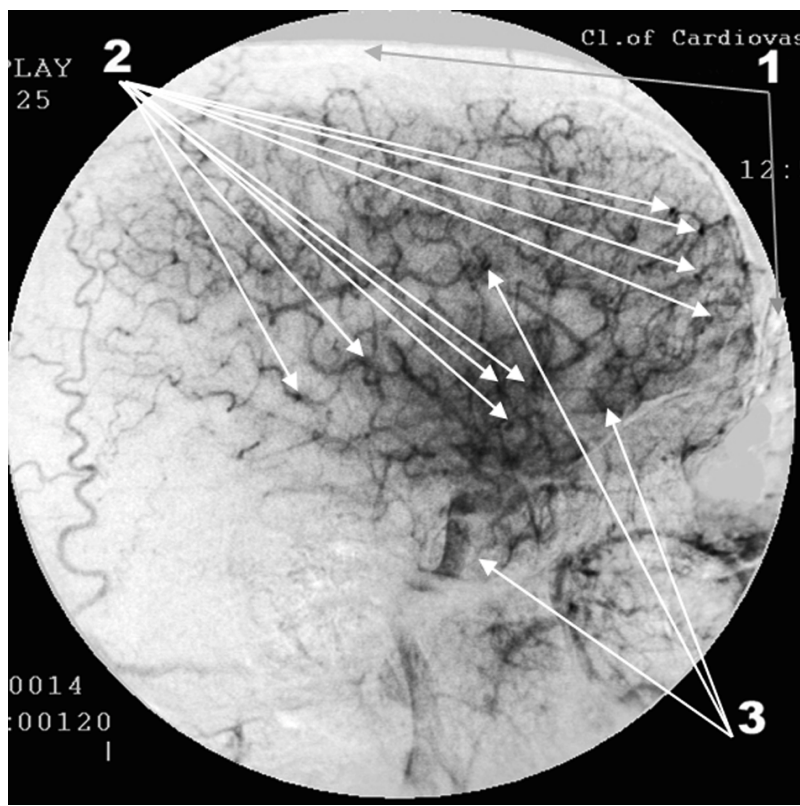

Figure 2. Patient O., 72 years old. Angiogram of the left internal carotid artery; TDR-2; lateral projection, capillary phase; Absence of atherosclerotic changes of intracranial vessels. 1: Development of hypovascular area; 2: Multiple arteriovenous shunts in fronto-parietal and temporal regions; 3: The development of early venous discharge in the temporal and fronto-parietal region. Simultaneous filling of arteries and veins.

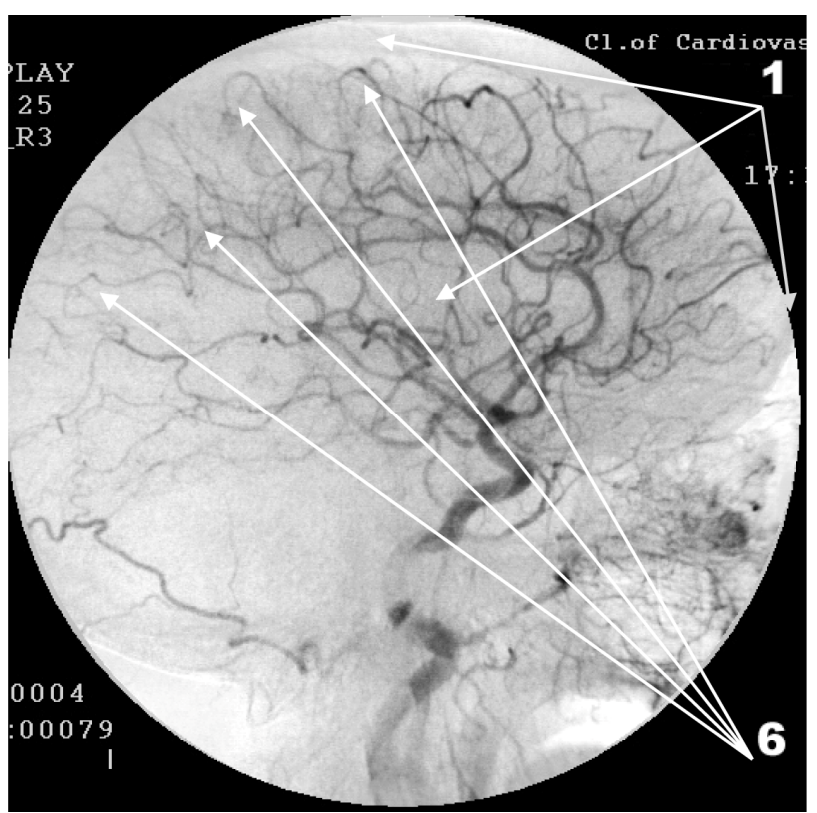

Figure 3. Patient P., 75 years old. Angiogram of the right internal carotid artery; TDR-3; lateral projection, early arterial phase; Absence of atherosclerotic changes of intracranial vessels. 1: Development of hypovascular area; 6: Multiple loop formation.

fronto-parietal regions were not detected in any case; - multiple arterio-venous shunts in the basin of the

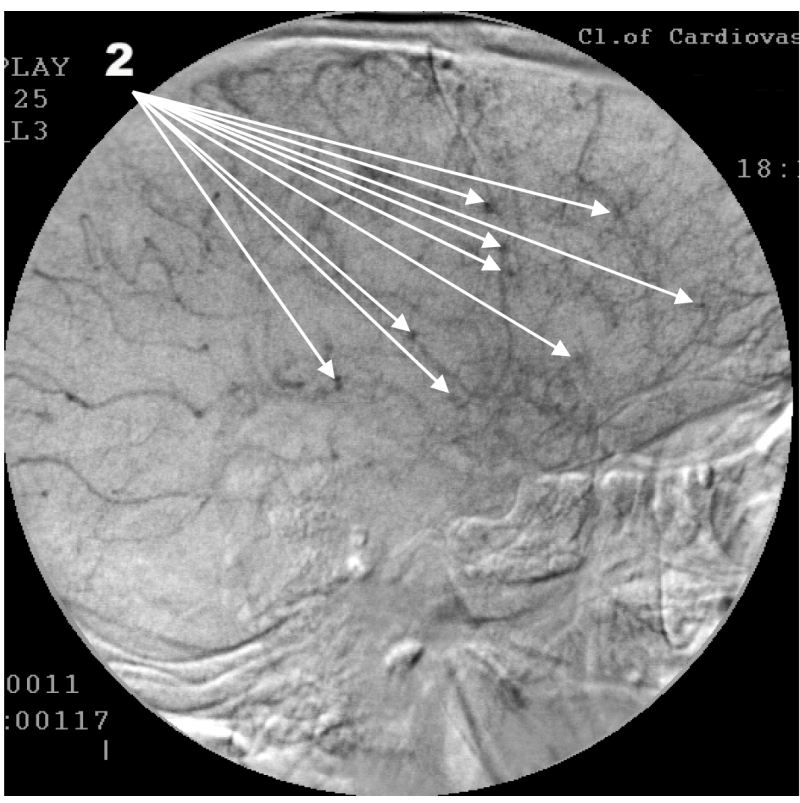

Figure 4. Patient P., 75 years old. Angiogram of the left internal carotid artery; TDR-3; lateral projection, capillary phase; 2 : Multiple arteriovenous shunts in fronto-parietal and temporal regions.

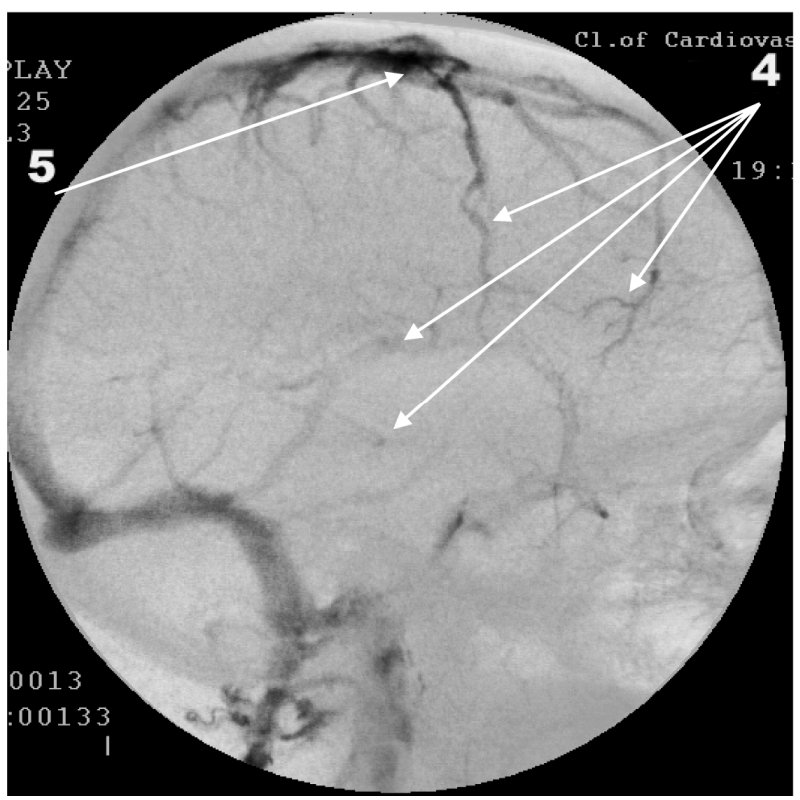

Figure 5. Patient P., 75 years old. Angiogram of the right internal carotid artery; TDR-3; lateral projection, venous phase; 4 : The development of pathologically enlarged veins that receive blood from arteriovenous shunts in the temporal and frontoparietal region; 5: Blood congestion on the border of the frontoparietal region.

front villous artery and in the basin of the arterial branches supplying the fronto-parietal cerebral cortex were not detected in any case;

- some scattered areas of low capillary contrast at the level of the white matter of the brain-36 (43.37\%) 


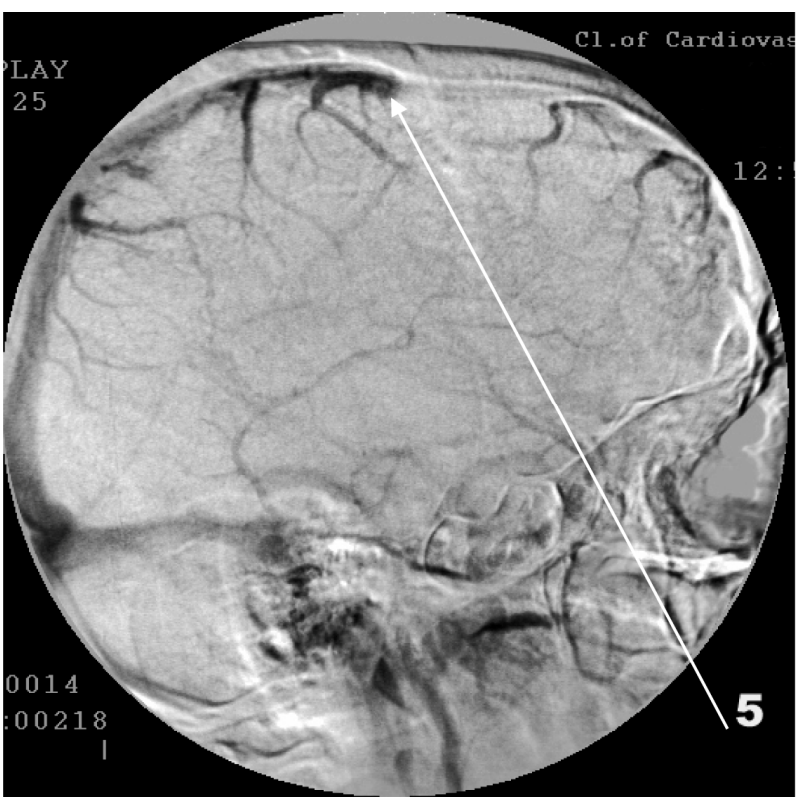

Figure 6. Patient S., 45 years old. Angiogram of the right internal carotid artery; TDR-1; lateral projection, venous phase; 5: Blood congestion on the border of the fronto-parietal region.

patients;

- multiple scattered arterio-venous shunts at the level of the white matter of the brain-37 (44.58\%) patients;

- scattered, mainly in the white matter, early venous dumping-38 (45.78\%) patients;

- development of abnormally enhanced venous trunks and anomalous venous congestion was not detected in any case;

- increased loop formation of distal intracranial arterial branches-5 $(6,02 \%)$ patients.

Thus, Control Group patients did not have any vascular and microcirculatory disorders of the brain similar to those detected among Test Group patients (Figures 7 and 8).

\section{DISCUSSION}

For antemortem studies of the brain vascular system, cerebral MUGA has been used. Due to its specificity and high image resolution, the method allows to obtain high quality vascular imaging and provides an opportunity for stepwise study of the state of the arterial, capillary, venous bed and the architectonics of the existing arterial and venous shunts and blood flows [20,21,30,32,50]. By means of this method we were able to detect AD-specific disorders of blood circulation and microcirculation in the temporal and fronto-parietal brain regions among Test Group patients.

We have named those disorders "dyscirculatory angiopathy of Alzheimer's type" (DAAT) [32,50]. They do not occur among Control Group patients, and they are specific for $\mathrm{AD}$ and non-specific for other neurodegen- erative diseases accompanied by the development of dementia and cognitive impairment.

DAAT is the combination of the following:

- reduction of the capillary bed in the temporal and fronto-parietal brain regions;

- development of multiple arterio-venous shunts in the basin of the front villous artery supplying the hippocampus and in the basin of the arterial branches supplying the fronto-parietal brain regions;

- early venous dumping of arterial blood through these shunts with simultaneous filling of the arteries and veins in the temporal and fronto-parietal regions;

- development of abnormally enlarged lateral venous branches that receive blood from the arterio-venous shunts in the temporal and fronto-parietal region;

- anomalous venous stasis on the border of the frontal and parietal lobe due to excessively high blood influx from the arterio-venous shunts;

- increased loop formation of distal intracranial arterial branches.

In fact, DAAT is a vascular sign of $\mathrm{AD}$ and is an important criterion in the differential diagnosis of neurodegenerative diseases $[21,32,50]$.

The obtained data concerning the capillary disorders in $\mathrm{AD}$ is confirmed by morphological studies conducted by S. J. Baloiannis and I. S. Baloiannis [51]. These authors used electron microscopy to reveal capillary degeneration and a significant decrease in the number of capillaries per cubic centimeter of the hippocampus tissue in patients with $\mathrm{AD}$ compared to the hippocampus tissue in people of the same age but without the disease.

In our opinion, DAAT progress begins with abnormalities of the cerebral microcirculation which are manifested in capillary bed reduction which leads to the reduction of arterial blood flow to the cerebral tissues. The result of it is chronic hypoperfusion of the temporal and fronto-parietal regions which causes AD-specific brain tissue hypoxia; that is also supported by other authors' studies [28]. The process of capillary bed reduction is accompanied by a compensatory opening of arterio-venous shunts which relieve the arterial bed by dumping blood to the venous bed.

Such compensatory opening of arterio-venous shunts is observed in various human organs and tissues during the reduction of arterial blood flow-for example, in peripheral arterial occlusions [52]. Opening arterio-venous shunts cause arterio-venous dumping and allow to balance the inflow and outflow of blood to the site with reduced arterial or capillary permeability.

With $\mathrm{AD}$, the overflow of arterial bed by venous blood leads to abnormal enlargement of the lateral veins of the temporal and fronto-parietal region and subsequent blood congestion.

These hemodynamic changes may in their turn affect 
Table 2. Vascular disorders of the brain identified among patients of the Test and Control Groups during MUGA.

\begin{tabular}{|c|c|c|c|}
\hline Number of Patients: N-164 & $\begin{array}{c}\text { Test Group } \\
\text { (Alzheimer's Disease): } \\
\text { N-81 }\end{array}$ & $\begin{array}{c}\text { Control Group } \\
\text { (Other Brain Lesions): } \\
\mathrm{N}-83 \\
\end{array}$ & p (Chi-Square) \\
\hline Atherosclerotic changes of intracranial arteries & 0 & 80 & $<0.005$ \\
\hline $\begin{array}{l}\text { Reduction of capillaries in the temporal } \\
\text { and fronto-parietal regions }\end{array}$ & 81 & 0 & $<0.005$ \\
\hline $\begin{array}{l}\text { Multiple arteriovenous shunts in the } \\
\text { temporal and fronto-parietal regions }\end{array}$ & 81 & 0 & $<0.005$ \\
\hline $\begin{array}{l}\text { Early venous dumping of arterial blood in the temporal and } \\
\text { fronto-parietal region }\end{array}$ & 81 & 0 & $<0.005$ \\
\hline $\begin{array}{l}\text { Development of abnormally enlarged lateral } \\
\text { venous branches in the temporal and fronto-parietal regions }\end{array}$ & 73 & 0 & $<0.005$ \\
\hline $\begin{array}{l}\text { Abnormal congestion of venous blood at the border } \\
\text { of the temporal and fronto-parietal lobe }\end{array}$ & 74 & 0 & $<0.005$ \\
\hline Increased loop-formation of distal intracranial branches & 64 & 5 & $<0.005$ \\
\hline Stenotic lesions of intracranial branches & 0 & 63 & $<0.005$ \\
\hline Occlusive lesions of intracranial branches & 0 & 22 & $<0.005$ \\
\hline $\begin{array}{l}\text { Scattered areas of low capillary contrast at } \\
\text { the level of the white matter of the brain }\end{array}$ & 0 & 36 & $<0.005$ \\
\hline $\begin{array}{l}\text { Scattered arteriovenous shunts at the } \\
\text { level of the white matter of the brain }\end{array}$ & 0 & 37 & $<0.005$ \\
\hline Early venous dumping in the white matter of the brain & 0 & 38 & $<0.005$ \\
\hline
\end{tabular}

An analysis of $2 \times 2$ contingency tables for each of the parameters under study was made using the chi-square test which showed statistically significant differences for each of the parameters under study.

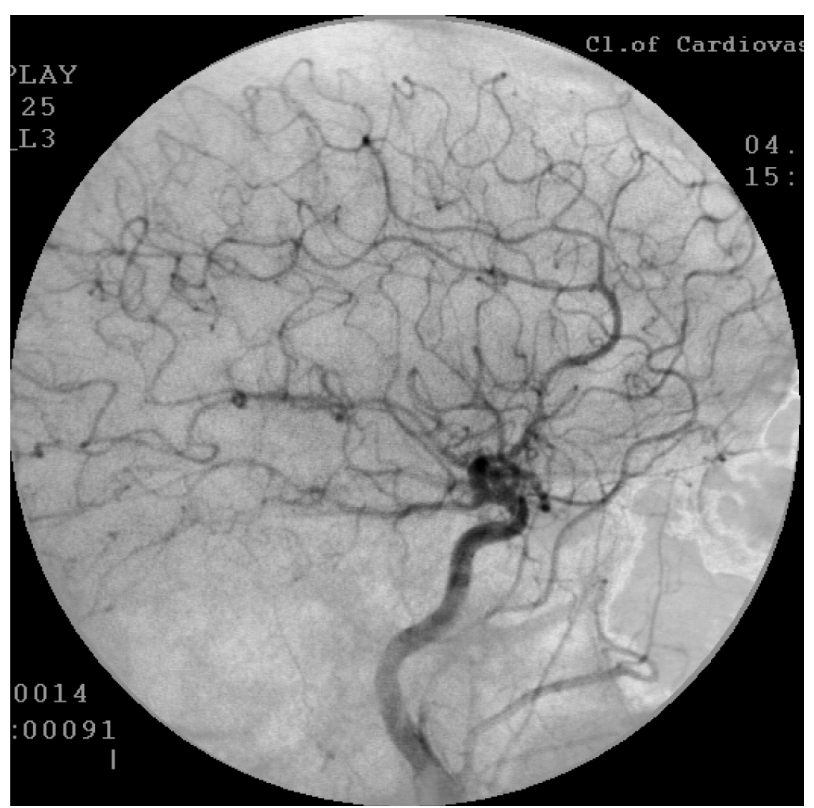

Figure 7. Patient P., 61 years old. Angiogram of the left internal carotid artery; lateral projection, arterial phase; Diagnosis: atherosclerosis of cerebral vessels, chronic cerebrovascular insufficiency, CDR-1 Mild atherosclerotic changes; Good opacification of capillaries, absence of hypovascular areas in the temporal and fronto-parietal regions; Absence of multiple arterio-venous shunts in the temporal and fronto-parietal regions; Absence of simultaneous filling of arteries and veins.

the metabolism of amyloid-beta and cause its deposition and accumulation in cerebral tissue thereby stimulating AD progression [21,30,32].

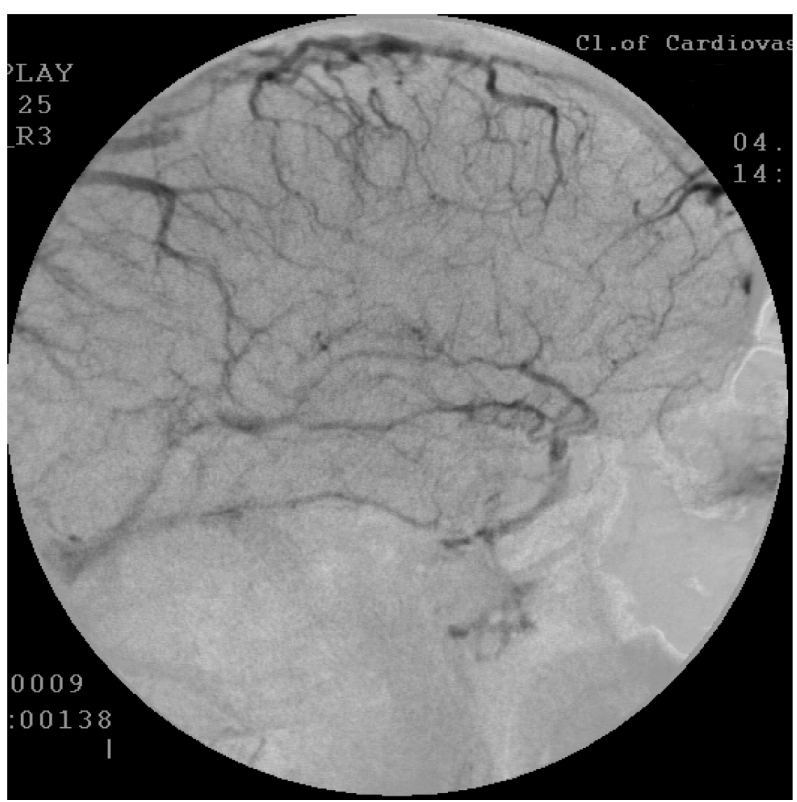

Figure 8. Patient P., 61 years old. Angiogram of the right internal carotid artery; lateral projection, venous phase; Diagnosis: atherosclerosis of cerebral vessels, chronic cerebrovascular insufficiency, CDR-1 Absence of pathologically enlarged veins that receive blood from arteriovenous shunts in the temporal and fronto-parietal region; Absence of blood congestion on the border of the fronto-parietal region.

Our hypothesis is confirmed by the work by B. V. Zlokovic et al. $[53,54]$ in which the authors, carrying out research on genetically modified mice, have shown that an experimental model of $\mathrm{AD}$ is characterized by the 
accumulation of vasculotoxic and neurotoxic molecules in the brain tissue which causes hemodynamic instability, reduces capillary blood flow and promotes the development of specific cerebral hypoxia. This process leads to an increase in accumulation and a decrease in removal of beta amyloid, subsequent dysfunction and neurodegeneration.

The data obtained resonate with research by A. Dorr et al. [26] conducted on transgenic mice with an experimental model of AD. In the study of the material the authors revealed degeneration, diameter reduction and increased sinuosity of microvessels in the cortex of tested animals which was interpreted as the result of betaamyloid deposition in the vascular wall and parovazal tissue.

According to our results obtained among Test Group patients, the severity of arterial, venous, and microvascular abnormalities does not depend on the timing of the onset of AD symptoms, severity of dementia or severity of cognitive impairment [21,30,32]. These abnormalities are almost equally observed among patients with clinical AD stages (TDR-1, TDR-2, TDR-3) and among those with a preclinical AD stage (TDR-0). Moreover, similar changes occur among children of 8-12 years of age and among AD patients' children [55,56]. It suggests that microvascular changes in the brain are likely to develop before the process of beta-amyloid deposition. It seems unlikely that in genetically determined and sporadic forms of $\mathrm{AD}$, beta-amyloid deposition in the vascular wall and brain tissue starts early, decades before any clinical manifestations of the disease.

Interestingly, there are studies that show that the high content of amyloid-beta in the brain tissue can be observed in healthy people and does not always lead to dementia and AD [57].

For antemortem studies of $\mathrm{CBF}$ and cerebral perfusion abnormalities in AD, SPECT, PET and MRI technologies are usually used being at present not sensitive enough to determine vascular and microcirculatory abnormalities, and therefore it is difficult to identify these abnormalities in $100 \%$ of cases $[27,58]$. In contrast to MUGA, these technologies do not allow to visualize the vascular system of the brain and to explore its parts locally determining the state of the arteries, capillaries and veins. They allow to determine total perfusion in a certain area, lobe or in the whole brain.

However, studies using SPECT and PET have shown that progression of $\mathrm{AD}$ and cognitive impairment is characterized by a progressive decline of CBF in the temporal, parietal and frontal regions [27,59]; we have obtained similar results not only by means of MUGA but also by means of SG and REG.

When using Perfusion MRI technologies to determine cerebral perfusion, it should be noted that this method, though more progressive compared to SPECT and PET, also does not allow to determine the state of the local vascular system in certain areas of the cerebral tissue. As a result, as well as when using SPECT and PET, total perfusion is determined in some area or lobe of the brain. This particularity of Perfusion MRI technology has led to the appearance of reports describing compensatory enhancement of cerebral perfusion at preclinical and early AD stages but persistent hypoperfusion in the later stages of the disease [27], which potentially confirms our data.

As we have already noted, DAAT progression leads to natural compensatory opening of arterio-venous shunts with sufficiently powerful dumping of arterial blood to the venous bed. Preclinical and early clinical AD stages progress at a younger age, when compensatory mechanisms regulating CBF are expressed better, the deposition of amyloid-beta in the brain tissue being quite small. In this case, when determining the perfusion by means of Perfusion MRI technology, total perfusion is visualized in the temporal lobes of the brain including the compensatory powerful dumping of arterial blood into the venous bed as well. As a result, the obtained numbers may exceed the norm. Obviously, that was what the authors have received interpreting it as enhanced perfusion due to more active work of arteries and capillaries. Late AD stages occur in old age, when compensatory mechanisms of $\mathrm{CBF}$ regulation decrease and there is high accumulation of amyloid-beta in the brain tissue which helps to reduce $\mathrm{CBF}$. As a result, the authors have observed the phenomenon of cerebral hypoperfusion which confirms our data.

Vascular and microvascular changes in AD are always associated with a decrease in size and with atrophic phenomena in the temporal and fronto-parietal brain regions $[32,47-50]$. It is interesting to note that the tendency for temporal lobes size reduction has been reported in new-born babies who have a high potential risk for the disease, from which the authors conclude that these changes begin to progress in utero [60].

These data indirectly confirm our hypothesis that DAAT is likely to develop before the deposition of amyloid-beta, its excretion process being affected, which may possibly lead to its accumulation. DAAT does not cause but only contributes to $\mathrm{AD}$, and may perhaps be congenital in nature $[55,56]$.

Thus, we can conclude that the reduction of the capillary bed, abnormal cerebral microcirculation, as well as the accumulation of amyloid-beta are interrelated processes that occur early enough, proceed for a long time, lead to hypotrophic and atrophic changes in the tissue of the temporal and fronto-parietal regions and finally cause AD.

The combination of these changes must be taken into consideration in the examination of patients with $\mathrm{AD}$, the 
monitoring of the disease course and, naturally, in the development of new methods for treating $\mathrm{AD}[21,28,30$, $32,36,42]$.

\section{REFERENCES}

[1] (2011) Cognitive impairment: A call for action, now! http://www.cdc.gov/aging/pdf/cognitive impairment/cogi mp_poilicy final.pdf

[2] (2013) Alzheimer's disease facts and figures. http://www.alz.org/downloads/facts_figures_2013.pdf

[3] Torack, R.M. (1979) Adult dementia: History, biopsy, pathology. Neurosurgery, 4, 434-442.

http://www.ncbi.nlm.nih.gov/pubmed/379682 http://dx.doi.org/10.1227/00006123-197905000-00011

[4] Carpenter, B. and Dave, J. (2004) Disclosing a dementia diagnosis: A review of opinion and practice, and a proposed research agenda. Geronotologist, 44, 149-158. http://www.ncbi.nlm.nih.gov/pubmed/15075411

[5] Waldemar, G., Dubois, B., Emre, M., Georges, J., McKeith, I.G., Rossor, M., Scheltens, P., Tariska, P. and Winblad, B. (2007) Recommendations for the diagnosis and management of Alzheimer's disease and other disorders associated with dementia: EFNS guideline. European Journal of Neurology, 14, e1-e26.

http://www.ncbi.nlm.nih.gov/pubmed/17222085

[6] Jack, C.R. Bentley, M.D. Twomey C.K. and Zinsmeister, A.R. (1990) MR imaging-based volume measurements of the hippocampal formation and anterior temporal lobe: Validation studies. Radiology, 176, 205-209. http://www.ncbi.nlm.nih.gov/pubmed/2353093

[7] Jack, C.R., Petersen, R.C., Xu, Y.C., et al. (1999) Prediction of AD with MRI-based hippocampal volume in mild cognitive impairment. Neurology, 52, 1397-1403. http://www.ncbi.nlm.nih.gov/pubmed/10227624

[8] Pietrini, P., Alexander, G.E., Furey, M.L., et al. (2000) Cerebral metabolic response to passive audiovisual stimulation in patients with Alzheimer's disease and healthy volunteers assessed by PET. Journal of Nuclear Medicine, 41, 575-583.

http://www.ncbi.nlm.nih.gov/pubmed/10768555

[9] Burton, E.J., Barber, R., Mukaetova-Ladinska, E.B., Robson, J., Perry, R.H., Jaros, E., Kalaria, R.N. and O'Brien, T.J. (2009) Medial temporal lobe atrophy on MRI differentiates Alzheimer's disease from dementia with Lewy bodies and vascular cognitive impairment: A prospective study with pathological verification of diagnosis. Brain, 132, 195-203.

http://www.ncbi.nlm.nih.gov/pubmed/?term=Burton\%2C + E.J.+Barber\%2C+R.+Mukaetova-Ladinska\%2C+E.B.+ Robson $\% 2 \mathrm{C}+\mathrm{J} .+$ Perry $\% 2 \mathrm{C}+$ R.H. + Jaros $\% 2 \mathrm{C}+\mathrm{E} .+$ Kalaria

[10] Trojanowski, J.Q., Vandeerstichele, H., Korecka, M., et al. (2010) Update on the biomarker core of the Alzheimer's disease neuroimaging initiative subjects. Alzheimer's \& Dementia, 6, 230-238.

http://www.ncbi.nlm.nih.gov/pubmed/20451871

[11] Perrin, R.J., Craig-Schapiro, R., Morris, J.C., et al. (2011) Identification and validation of novelcerebrospinal fluid biomarkers for staging early Alzheimer's disease. Public Library of Science One, 12, Article ID: e16032. http://www.ncbi.nlm.nih.gov/pmc/articles/PMC3020224/ ?tool=pmcentrez

[12] Adriaase, A., Sanz-Arigita, E., Binnewijzend, M., et al. (2011) Molecular markers of Alzheimer's disease pathology and their relationship with default mode network integrity. Alzheimer's \& Dementia, 7, S2-S3.

http://www.alzheimersanddementia.com/article/S1552-52 60(11)00144-0/fulltext

[13] Meyer, P.T., Hellwig, S., Amtage, F., et al. (2011) Dualbiomarker imaging of regional cerebral amyloid load and neuronal activity in dementia with PET and 11C-labeled Pittsburgh compound B. Journal of Nuclear Medicine, 52, 393-400. http://www.ncbi.nlm.nih.gov/pubmed/21321269

[14] Morel, F. (1950) An apparently dyshoric and topical angiopathy. Monatsschrift für Psychiatrie und Neurologie, 120, 352-357.

http://www.ncbi.nlm.nih.gov/pubmed/14806299

[15] Di Carlo, A., Baldereschi, M., Amaducci, L., et al. (2002) Incidence of dementia, Alzheimer's disease, and vascular dementia in Italy. The ILSA study. Journal of the American Geriatrics Society, 50, 41-48.

http://www.ncbi.nlm.nih.gov/pubmed/12028245 http://dx.doi.org/10.1046/j.1532-5415.2002.50006.x

[16] De la Torre, J.C. (1997) Hemodynamic consequences of deformed microvessels in the brain in Alzheimer's disease. Annals of New York Academy Sciences, 26, 75-91. http://www.ncbi.nlm.nih.gov/pubmed/9329682?dopt=Abs $\underline{\text { tract }}$

[17] Skoog, I., Kalaria, R.N. and Breteler, M.M. (1999) Vascular factors and Alzheimer disease. Alzheimer Disease and Associated Disorders, 13, 106-114.

http://www.ncbi.nlm.nih.gov/pubmed/10609689 http://dx.doi.org/10.1097/00002093-199912003-00016

[18] De la Torre, J.C. and Stefano, G.B. (2000) Evidence that Alzheimer's disease is a microvascular disorder: The role of constitutive nitric oxide. Brain Research Reviews, 34, 119-136.

http://europepmc.org/abstract/MED/11113503/reload=0; js essionid=gQgXaQg9i1yxSODYLdkV.0 http://dx.doi.org/10.1016/S0165-0173(00)00043-6

[19] Kalaria, R.N. (2000) Vascular factors in Alzheimer's disease. New York Academy of Sciences, New York. http://books.google.ru/books?id=jHZFAAAAYAAJ\&hl=r $\underline{\mathrm{u} \& \text { source }=\mathrm{gbs} \text { book_similarbooks }}$

[20] Maksimovich, I.V. and Gotman, L.N. (2006) Method of complex radiation diagnostics at preclinical and clinical stages of Alzheimer's disease. Russian Patent No. 2315559. http://bankpatentov.ru/node/28577

[21] Maksimovich, I.V. (2008) Radiodiagnostics of Alzheimer's disease. Diagnostics and Intervention Radiology, 2, 27-38.

http://www.radiology-di.ru/articles/155/126/tom-2-N4-20 08.html

[22] Di Iorio, A., Zito, M., Lupinetti, M. and Abate, G. (1999) Are vascular factors involved in Alzheimer's disease? Facts and theories. Aging, 11, 345-352.

http://www.ncbi.nlm.nih.gov/pubmed/10738848 
[23] Kalaria, R.N. (2002) Small vessel disease and Alzheimer's dementia: Pathological considerations. Cerebrovascular Diseases, 13, 48-52. http://www.ncbi.nlm.nih.gov/pubmed/11901243

[24] Maksimovich, I.V., Gotman, L.N. and Masyuk, S.M. (2004) Transluminal laser angioplastics for treatment of microcirculatory abnormalities in Alzheimer's disease. Angiology and Vascular Surgery, 10, 89-90. http://www.angiologia.ru/

[25] Mielke, M.M., Rosenberg, P.B., Tschanz, J.L. Cook, L., et al. (2007) Vascular factors predict rate of progression in Alzheimer disease. Neurology, 6, 1850-1858. http://www.neurology.org/content/69/19/1850.short

[26] Dorr, A., Sahota, B., Chinta, L.V., Brown, M.E., Lai, A.Y., Ma, K., Hawkes, C.A., Mc Laurin, J. and Stefanovic, B. (2012) Amyloid- $\beta$-dependent compromise of microvascular structure and function in a model of Alzheimer's disease. Brain. 135, 3039-3050.

http://www.ncbi.nlm.nih.gov/pubmed/23065792 http://dx.doi.org/10.1093/brain/aws243

[27] Chen, W., Song, X., Beyea, S., D’Arcy, R., Zhan, Y. and Rockwood, K. (2011) Advances in perfusion magnetic resonance imaging in Alzheimer's disease. Alzheimer's \& Dementia, 7, 185-186.

http://www.alzheimersanddementia.com/article/S1552-52 60(10)00105-6/abstract

[28] Grammas, P., Sanchez, A., Tripathy, D., Luo, E. and Martinez, J. (2011) Vascular signaling abnormalities in Alzheimer disease. Cleveland Clinic Journal of Medicine, 78, 50-53. http://www.ccjm.org/content/78/Suppl 1/S50.full http://dx.doi.org/10.3949/cjm.78.s1.09

[29] Kalaria, R.N. (2003) Vascular factors in Alzheimer's disease. International Psychogeriatrics, 15, 47-52. http://www.ncbi.nlm.nih.gov/pubmed/16191216 http://dx.doi.org/10.1017/S1041610203008950

[30] Maksimovich, I.V. (2009) Changes in angioarchetectonics of brain at Alzheimer's disease. The Neurologic Bullet, XLI, 9-14. http://www.infamed.com/nb/2 2009 9-14.pdf

[31] Altman, R. and Rutledge, J.C. (2010) The vascular contribution to Alzheimer's disease. Clinical Science, 119, 407-421.

http://www.ncbi.nlm.nih.gov/pmc/articles/PMC2950620/ ?tool=pubmed http://dx.doi.org/10.1042/CS20100094

[32] Maksimovich, I.V. (2012) Vascular factors in Alzheimer's disease. Health, 4, 735-742.

http://www.scirp.org/journal/PaperInformation.aspx?pape $\mathrm{rID}=23274$ http://dx.doi.org/10.4236/health.2012.429114

[33] Kalaria, R.N., Akinyemi, R. and Ihara, M. (2012) Does vascular pathology contribute to Alzheimer changes? Journal of the Neurological Sciences, 322, 141-147. http://www.ncbi.nlm.nih.gov/pubmed/22884479

[34] Cameron, D.J., Galvin, C., Alkam, T., Sidhu, H., Ellison, J., Luna, S. and Ethell, D.W. (2012) Alzheimer's related peptide amyloid- $\beta$ plays a conserved role in angiogenesis. PLoS One, 7, Article ID: e39598.

http://www.ncbi.nlm.nih.gov/pubmed?term=Alzheimer'sRlated\%20Peptide $\% 20$ Amyloid $\%$ CE $\%$ B2\%20Plays $\% 20 \mathrm{a}$
$\% 20$ Conserved $\% 20$ Role $\% 20$ in $\% 20$ Angiogenesis http://dx.doi.org/10.1371/journal.pone.0039598

[35] De la Torre, J.C. (2012) A turning point for Alzheimer's disease? Biofactors, 38, 78-83.

http://www.ncbi.nlm.nih.gov/pubmed?term=De $\% 201 \mathrm{a} \% 2$ 0Torre\%20J.\%20C.\%20(2012)\%20A\%20turning\%20poin t\%20for $\% 20$ Alzheimer's $\% 20$ disease $\% 3 \mathrm{~F}$ http://dx.doi.org/10.1002/biof.200

[36] Otergaard, L., Aamand, R., Gutiérrez-Jiménez, E., Ho, Y.C., Blicher, J.U., Madsen, S.M., Nagenthiraja, K., Dalby, R.B., Drasbek, K.R., Moller, A., Breandgaard, H., Mouridsen, K., Jespersen, S.N., Jensen, M.S. and West, M.J. (2013) The capillary dysfunction hypothesis of Alzheimer's disease. Neurobiology of Aging, 34, 1018-1031. http://www.ncbi.nlm.nih.gov/pubmed/23084084 http://dx.doi.org/10.1016/j.neurobiolaging.2012.09.011

[37] Albert, M.S., DeKosky, S.T., Dickson, D., et al. (2011) The diagnosis of mild cognitive impairment due to Alzheimer's disease: Recommendations from the National Institute on Aging - Alzheimer's Association workgroups on diagnostic guidelines for Alzheimer's disease. Alzheimer's \& Dementia, 7, 270-279.

http://www.alzheimersanddementia.com/article/S1552-52 60(11)00104-X/abstract http://dx.doi.org/10.1016/j.jalz.2011.03.008

[38] Jack, C.R., Albert, M.S., Knopman, D.S., McKhann, G.M., Sperling, R.A., Carrillo, M.C., Thies, B. and Phelps, C.H. (2011) Introduction to the recommendations from the National Institute on Aging-Alzheimer's Association workgroups on diagnostic guidelines for Alzheimer's disease. Alzheimer's \& Dementia, 7, 257-262. http://www.alzheimersanddementia.com/article/S1552-52 60(11)00100-2/abstract http://dx.doi.org/10.1016/j.jalz.2011.03.004

[39] Higuchi, Y., Miyakawa, T., Shimoji, A. and Katsugari, S. (1987) Ultrastructural changes of blood vessels in the cerebral cortex in Alzheimer's disease. The Japanese Journal of Psychiatry Neurology, 41, 283-290. http://www.ncbi.nlm.nih.gov/pubmed/3437617

[40] Baloyannis, S.J. (2009) Dendritic pathology in Alzheimer's disease. Journal of the Neurological Sciences, 283, 153-157.

http://www.ncbi.nlm.nih.gov/pubmed/19296966 http://dx.doi.org/10.1016/j.jns.2009.02.370

[41] Deane, R., Bell, R.D., Sagare, A. and Zlokovic, B.V. (2009) Clearance of amyloid-beta peptide across the blood-brain barrier: Implication for therapies in Alzheimer's disease. CNS \& Neurological Disorders Drug Targets, 8, 16-30. http://www.ncbi.nlm.nih.gov/pubmed/19275634 http://dx.doi.org/10.2174/187152709787601867

[42] Maksimovich, I.V. (2010) Dyscirculatory angiopathy of the brain of Alzheimer's type. Alzheimer's \& Dementia, $\mathbf{6}$, e34.

http://www.alzheimersanddementia.com/article/S1552-52 60(10)02300-9/fulltext http://dx.doi.org/10.1016/j.jalz.2010.08.108

[43] Nishimura, T., Hashikawa, K., Fukuyama, H., Kubota, T., Kitamura, S., Matsuda, H., Hanyu, H., Nabatame, H., Oku, N., Tanabe, H., Kuwabara, Y., Jinnouchi, S. and Kubol, A. (2007) Decreased cerebral blood flow and prognosis of 
Alzheimer's disease: A multicenter HMPAO-SPECT study. Annals of Nuclear Medicine, 21, 15-23.

http://www.ncbi.nlm.nih.gov/pubmed/17373332 http://dx.doi.org/10.1007/BF03033995

[44] Folstein, M.F., Folstein, S.E. and McHugh, P.R. (1975) "Mini-Mental state". A practical method for grading the cognitive state of patients for the clinician. Journal of Psychiatric Research, 12, 189-198. http://www.ncbi.nlm.nih.gov/pubmed/1202204

[45] Morris, J.C. (1993) The Clinical Dementia Rating (CDR): Current version and scoring rules. Neurology, 43, 24122414.

http://www.ncbi.nlm.nih.gov/pubmed/8232972 http://dx.doi.org/10.1212/WNL.43.11.2412-a

[46] Maksimovich, I.V. (2012) The tomography dementia rating scale: Morphologically determined scale of Alzheimer's disease stages. Alzheimer's \& Dementia: The Journal of the Alzheimer's Association, 8, P335-P336. http://www.alzheimersanddementia.com/article/S1552-52 60(12)01059-X/fulltext

[47] Maksimovich, I.V. (2012) The tomography dementia rating scale (TDR) - The rating scale of Alzheimer's disease stages. Health, 4, 712-719.

http://www.scirp.org/journal/PaperInformation.aspx?Pape rID $=23257$

http://dx.doi.org/10.4236/health.2012.429111

[48] Maksimovich, I.V. (2012) Morphologically determined scale of Alzheimer's disease stages - The tomography dementia rating scale (TDR). Diagnostics and Intervention Radiology, 6, 23-32.

http://www.radiology-di.ru/articles/179/303/tom-6-N4-20 12.html

[49] Maksimovich, I.V. (2013) A morphologically based scale of Alzheimer's disease stages "the tomography dementia rating scale" (TDR). European Psychiatry, 28, 1.

http://www.sciencedirect.com/science/article/pii/S092493 $\underline{3813762497}$ http://dx.doi.org/10.1016/S0924-9338(13)76249-7

[50] Maksimovich, I.V. (2011) Dyscirculatory angiopathy of Alzheimer's type. Journal of Behavioral and Brain Science, 1, 57-68.

http://www.scirp.org/journal/PaperInformation.aspx?pape rID $=4630$

http://dx.doi.org/10.4236/jbbs.2011.12008

[51] Baloiannis, S.J. and Baloiannis, I.S. (2012) The vascular factor in Alzheimer's disease: A study in Golgi technique and electron microscopy. Journal of the Neurological Sciences, 322, 117-121.

http://www.jns-journal.com/article/S0022-510X(12)0034 4-9/abstract

http://dx.doi.org/10.1016/j.jns.2012.07.010

[52] Kuleshov, E.V. and Maksimovich, I.V. (1994) Endovascular surgery in patients over 65 with disseminated athero- sclerosis of the vessels of the pelvis and lower extremities. Vestnik Khirurgii Imeni I. I. Grekova, 152, 27-30. http://www.ncbi.nlm.nih.gov/pubmed/7701734

[53] Bell, R.D. and Zlokovic, B.V. (2009) Neurovascular mechanisms and blood-brain barrier disorder in Alzheimer's disease. Acta Neuropathologica, 118, 103-113. http://www.ncbi.nlm.nih.gov/pubmed/19319544 http://dx.doi.org/10.1007/s00401-009-0522-3

[54] Zlokovic, B.V. (2011) Neurovascular pathways to neurodegeneration in Alzheimer's disease and other disorders. Nature Reviews. Neuroscience, 12, 723-738. http://www.ncbi.nlm.nih.gov/pubmed/22048062

[55] Maksimovich, I.V. and Polyaev, Y.A. (2010) The importance of early diagnosis of dyscircular angiopathy of Alzheimer's type in the study of heredity of Alzheimer's disease. Alzheimer's \& Dementia, 6, e43.

http://www.alzheimersanddementia.com/article/S1552-52 60(10)02325-3/fulltext http://dx.doi.org/10.1016/j.jalz.2010.08.133

[56] Maksimovich, I.V. (2012) Certain new aspects of etiology and pathogenesis of Alzheimer's disease. Advances in Alzheimer's Disease, 1, 68-76.

http://www.scirp.org/journal/PaperInformation.aspx?Pape $\underline{\mathrm{rID}=25962}$

[57] Chételat, G., Villemagne, V.L., Pike K.E., Ellis, K.A., Ames, D., Masters, C.L. and Rowe, C.C. (2012) Relationship between memory performance and $\beta$-amyloid deposition at different stages of Alzheimer's disease. Neurodegenerative Diseases, 10, 141-144.

http://www.ncbi.nlm.nih.gov/pubmed/22301812 http://dx.doi.org/10.1159/000334295

[58] Provenzano, F.A., Muraskin, J., Tosto, G., Narkhede, A., Wasserman, B.T., Griffith, E.Y., Guzman, V.A., Meier, I.B., Zimmerman, M.E. and Brickman, A.M. (2013) White matter hyperintensities and cerebral amyloidosis: Necessary and sufficient for clinical expression of Alzheimer disease? JAMA Neurology, 70, 455-461. http://www.ncbi.nlm.nih.gov/pubmed/23420027

[59] Nishimura, T., Hashikawa, K., Fukuyama, H., Kubota, T., Kitamura, S., Matsuda, H., Hanyu, H., Nabatame, H., Oku, N., Tanabe, H., Kuwabara, Y., Jinnouchi, S. and Kubol, A. (2007) Decreased cerebral blood flow and prognosis of Alzheimer's disease: A multicenter HMPAOSPECT study. Annals of Nuclear Medicine, 21, 15-23. http://www.ncbi.nlm.nih.gov/pubmed/17373332 http://dx.doi.org/10.1007/BF03033995

[60] Knickmeyer RC, Wang J, Zhu H, Geng X, Woolson S, Hamer RM, Konneker T, Lin W, Styner M, Gilmore JH. (2013) Common variants in psychiatric risk genes predict brain structure at birth. Cerebral Cortex, 1, 2 . http://cercor.oxfordjournals.org/content/early/2013/01/02/ cercor.bhs401.abstract 